do after a missile attack and role acquisition. The quality of training was found to contribute to reducing anxiety with the knowledge variable as a mediator.

Conclusions People under attack, who learnt first-aid while in bomb-shelters, perceived themselves as caregivers and not as potential targets of attack themselves. Learning firstaid is seen as a mode to enable helping loved-ones, but not as a way of reducing anxiety among trainees. The professional level of training significantly influences the level of knowledge, and thus decreases anxiety. The aspiration to use good instructors always exists. This study emphasises the great importance of assigning appropriate instructors in such situations.

\title{
0911 THE DUAL BENEFIT OF FIRST AID TRAINING AMONG CIVILIANS IN A TIME OF WAR
}

E Jaffe*, E Aviel, N Kodinsky, H Knobler, L Aharonson-Daniel Correspondence: Magen David Adom International Institute, C/O Department of Emergency Medicine, BGU P.0. Box 653, Beer Sheva 84105, Israel

10.1136/ip.2010.029215.911

Background First-aid training enables the acquisition of lifesaving skills. However, proficiency in first-aid also reduces anxiety among caregivers. The question explored in this study was as follows: Will first-aid training in shelters to civilians under missile attacks contribute to reducing anxiety among the trainees beyond the provision of life-saving skills?

Methods Participants of first-aid training courses conducted in shelters in settlements under missile attack in southern Israel during January 2009 were asked about their reason for joining the course, the quality of training, the courses' influence on their perceived role during a missile attack and their self perceived proficiency with life-saving skills.

Results 140 respondents, residents of 28 southern settlements of whom $77 \%$ were female. The training course significantly contributed to the feeling of safety, the knowledge what to 